\title{
STRATEGI PENGHIMPUNAN DANA SOSIAL UMMAT PADA LEMBAGA-LEMBAGA FILLANTROFI DI INDONESIA (Studi Kasus Dompet Peduli Ummat Daarut Tauhid, Dompet Dhuafa Republika, BAZNAS, dan BAZIS DKI Jakarta)
}

\author{
N.Oneng Nurul Bariyah \\ Dosen Universitas Muhammadiyah Jakarta \\ E-mail: noerfai@yahoo.co.id
}

\begin{abstract}
This study aimed to describe forms of fundrising conducted by institutions fillantrofi in Indonesia. The study was conducted at four institutions namely DPU Daarut Tauhid, Dompet Dhuafa Republika, BAZNAS, and BAZIS of DKI Jakarta. Source of data obtained from interviews and documentation. Data was analyzed using qualitative deskripstif. The results showed that the forms of fund raising undertaken, namely: Media usedprint, electronic, internet, and media communication. In this case there are several ways, namely: Media compaign, direct mail, telefundrinsing, direct fundrising, cooperation program, special event, religious fund, zakat collectors forming units (UPZ), CSR and CSR Cooperation Program, donation ritail humanitarian fund, through bank: ATM (transfers, phone and internet banking), service zakat donations via SMS and online.
\end{abstract}

Keywords: Fundrising, humanitarian, cooperationand service donation.

\begin{abstract}
Abstrak
Penelitian ini bertujuan untuk mendeskripsikan bentuk-bentuk penghimpunan dana (fundrising) yang dilakukan oleh lembaga-lembaga fillantrofi di Indonesia. Penelitian dilakukan pada empat lembaga yaitu DPU Daarut Tauhid, Dompet Dhuafa Republika, $B A Z N A S$, dan BAZIS DKI Jakarta. Sumber data diperoleh dari wawancara dan studi dokumentasi. Analisis data dilakukan dengan deskripstif kualitatif. Hasil penelitian menunjukkan bahwa bentuk-bentuk penghimpunan dana yang dilakukan, yaitu: Media yang digunakan: Cetak, elektronik, internet, dan media komunikasi. Dalam hal ini ada beberapa cara, yaitu: Media Compaign, Direct Mail, Telefundrinsing, Direct fundrising, kerjasama program, Special event, Religius Fund, Pembentukan Unit Pengumpul Zakat (UPZ), Kerjasama Program PKBL dan CSR, Donasi ritail dana kemanusiaan, Melalui bank: ATM (transfer, phone dan internet banking), layanan donasi lewat sms dan Zakat on-line.
\end{abstract}

Kata Kunci: Penghimpunan dana, kemanusiaan, kerjasamadan layanandonasi. 


\section{A. Pendahuluan}

Penghimpunan atau biasa dikenal dengan istilah fundrising merupakan kegiatan dalam rangka penghimpunan dana dan sumber daya lainnya dari masyarakat baik individu, kelompok, organisasi, perusahaan atau pemerintah. Dana tersebut akan digunakan untuk membiayai program dan kegiatan operasional lembaga dalam rangka mencapai tujuan (Juwaini, 2005: 4). Dengan demikian kegiatan fundrising bertujuan untuk menghimpun dana dari donatur yang sifatnya mendukung kegiatan sebuah lembaga.

Bentuk-bentuk fundrising yang dilakukan terkadang berbeda antar lembaga sesuai dengan visi dan misi serta mitra yang dibangun. Karena itu, fundrising dapat juga menjadi sarana untuk menghimpun simpatisan dan pendukung, bahkan .membangun citra lembaga sehingga memberikan kepuasan bagi para donatur dan akan meningkatkan kepercayaan.

Di Indonesia banyak muncul lembaga amal (fillantrofi) berbasis keagamaan dimana dana yang dikumpulkan merupakan dana amal yang menjadi bagian dari perintah agama yaitu zakat, infak, shadaqah (ZIS) dan wakaf. Keberadaan lembaga fillantropi yang berbasis keagaman tentu memiliki visi dan misi sesuai dengan tujuan dibentuknya lembaga tersebut. Berikut ini akan dipaparkan model penghimpunan danayang dilakukan oleh beberapa lembaga filantrofi berbasis keagamaan yaitu DPU Daarut Tauhid, Dompet Dhu'afa, BAZNAS, dan BAZIS DKI Jakarta.

\section{B. Strategi Penghimpunan Dana Ummat}

1. Dompet Peduli Umat (DPU) Daarut Tauhid

Dompet Peduli Ummat (DPU)) Daarut Tauhid sebuah Lembaga Amil Zakat (LAZ) dan merupakan lembaga nirlaba yang bergerak di bidang penghimpunan (fundrising) dan pendayagunaan dana zakat, infaq, shadaqah dan wakaf (ZISWA). DPU Daarut Tauhid didirikan pada tanggal 16 Juni 1999 oleh KH. Abdullah Gymnastiar (AA Gym). Berawal dari rapat Pengurus yayasan pada tanggal 16 Juni 1999 yang memandang perlu adanya dana ZIS yang dikelola oleh pesantren Daarut Tauhid dengan mengoptimalkan jamaah pesantren Daarut Tauhid.

Atas hal tersebut dibentuklah DPU Daarut Tauhid yang mendapat legal formal dengan pengukuhannya oleh Gubernur Jawa Barat tanggal 19 Agustus 2002. Tahun 2004 DPU Daarut Tauhid menjadi LAZNAS tanggal 13 Oktober 2004 dengan SK Menteri Agama No. 410 Tahun 2004. DPU Daarut Tauhid menjadi lembaga fundrising dimulai setelah pengurus yayasan mengadakan kunjungan ke Yayasan Dana Sosial Al-Falah (YSDF) Surabaya pada acara silaturrahmi donatur-donatur YDSF. Setelah itu, Aa Gym membuat brosur penawaran untuk menjadi 
donatur tetap DPU sebanyak 10.000 lembar. DPU Daarut Tauhid bertekad menjadi LAZ yang amanah, professional dan jujur berlandaskan ukhuwwah Islamiyah.

$\begin{array}{lrr}\text { Kedudukan DPU } & \text { Daarut } \\ \text { Tauhid menjadi kuat dengan } \\ \text { diperolehnya SK Menteri } & \text { Agama } \\ \text { sehingga menjadikan DPU Daarut } & \text { Dantid semakin leluasa } & \text { untuk } \\ \text { Tauhid } & \text { kegiatan } & \text { dalam } \\ \text { melakukan danghimpunan dan penyaluran dana }\end{array}$
ZIS. Keberadaan DPU Daarut Tauhid sebagai LAZNAS memiliki program antara lain pemberdayaan masyarakat, hal tersebut berkaitan erat dengan keberadaan Daarut Tauhid yang latar belakang lahirnya diawali oleh Keluarga Mahasiswa Islam Wiraswasta pada tahun 1987 (www.dpu-online.com. 25/10/2010). Kelompok tersebut dikoordinir oleh Abdullah Gymnastiar dengan merintis usaha kecil percetakan, agen koran, dan lain-lain. Usaha mereka semakin berkembang karena banyak masyarakat yang tergabung sehingga pada tanggal 4 September 1990 dibentuklah Yayasan Daarut Tauhid. Pusat Kegiatan kelompok tersebut berada di Geger Kalong dengan menyewa rumah kost yang berkamar 20, sebelumnya digunakan untuk kost mahasiswa. Tempat ini merupakan tempat kegiatan yayasan membangun pesantren (Lembaga Pendidikan Islam) yang menjadi kegiatan pendidikan, ekonomi, dan dakwah. Menjelang akhir 1997, sarana perekonomian Daarut Tauhid menjadi lengkap dengan dibangunnya gedung Kopontren berlantai 4. Pada tahun 1998 Daarut Tauhid melengkapi unit usaha dengan mendirikan Cottage Daarul Jannah. Dari berbagai unit usaha yang ada diperoleh penghasilan lebih dari 400 juta perbulan. Nilai assetnya pada tahun 2000 mencapai Rp 8 miliar. Berdasarkan uraian tersebut, DPU Daarut Tauhid yang menjadi bagian dari Yayasan Pesantren Daarut Tauhid menjadikannya sebagai LAZ yang memiliki kekhasan tersendiri.

Dalam hal penggalangan dana, sejak awal hingga saat ini DPU Daarut Tauhid melakukan beberapa strategi, yaitu: kencleng umat, kerjasama dengan Radio Paramuda 93.9 FM, kampanye di radio, dan religius fund. Dinamakan demikian karena pengumpulan dana dilakukan dalam kegiatan keagamaan seperti pengajian (Hasil wawancara dengan Asep Hikmat Manajer Fundrising dan Sekretariat).

Selain itu, DPU Daarut Tauhid juga menggunakan strategi lain seperti, Direct Mail, Media Campaign, Membership, Corporate Fund, dan Earned Income (unit usaha yang dikelola dari berbagai sumbangan yang diberikan oleh perusahaan). Jemput ZIS, dan Timsil (Tim Silaturrahim) dimana petugas langsung menemui muzakki. Sampai saat ini, DPU Daarut Tauhid 
menerbitkan media cetak bernama majalah swadaya dan leaflet. Zakat juga dapat sampaikan lewat website atau Facebook.

Berdasarkan uraian di atas, metode dan strategi yang digunakan Dompet Peduli Ummat Daarut Tauhid yang paling berpengaruh di awal adalah adanya kencleng umat yang dimotori oleh Aa Gym. Ceramah agama yang disampaikan Aa Gym dapat menumbuhkan rasa keberagamaan para pendengar sehingga dapat mengumpulkan dana yang cukup besar. Terkumpulnya dana yang cukup besar itu tidak terlepas dari sikap keberagamaan para pendengar dakwah yang disampaikan Aa Gym.

Sementara layanan donasi saat ini (tahun 2009) dilakukan melalui: kantor (office), bank, kata (kotak amal tabungan akhirat), jemput ZIS, wesel pos, kalimat (kotak amal peduli umat), sorban wakaf, voucher infak, SMS Donasi Nasional, dan SMS Banking mandiri (www.dpu-online.com.25/01/2012). Media yang banyak akan memudahkan para donatur untuk berinfak. Selain itu, media infak yang tersedia dapat dilakukan mulai dari recehan rupiah sampai pada uang yang berjumlah besar. Ini artinya, orang yang berinfak pun tidak hanya orang yang memiliki uang banyak, orang yang memiliki sedikit uang tetapi ingin berinfak bisa dilakuan lewat kencleng umat.
Strategi penggalangan dana melalui kencleng umat banyak dilakukan masyarakat. Banyak masyarakat menggunakan kencleng umat untuk menggalang dana bagi pembangunan masjid. Tampaknya hal tersebut sederhana, tetapi memotivasi orang untuk berinfak walaupun dalam jumlah yang sangat sedikit.

Sarana dakwah sebagai
strategi penggalangan dana sebenarnya bukan hal baru, banyak penceramah yang diundang panitia pembangunan mesjid atau pondok pesantren guna menggalang dana bantuan. Khusus dalam penggalangan dana sosial umat, DPU Daarut tauhid dapat dijadikan model bagi lembaga lain yang serupa dalam penggalangan dana, karena telah memiliki "konstituen" yang tetap yaitu Majelis Taklim. Maka, strategi menggalang dana melalui Majelis Taklim dapat dijadikan model pada majelis Taklim yang ada di seluruh wilayah Nusantara. Strategi lain melalui media cetak, elektronik, silaturrahim merupakan startegi penggalangan dana yang dapat dijadikan model sesuai dengan kondisi yang ada.

\section{Dompet Dhuafa Republika}

Dompet Dhuafa Republika (DD Republika) dibentuk oleh komunitas jurnalis yang banyak berinteraksi dengan masyarakat miskin, sekaligus kerap jumpa 
dengan kaum kaya. Komunitas jurnalis tersebut yaitu Parni Hadi, Haidar Bagir, S. Sinansari Ecip, dan Eri Sudewo berpadu sebagai Dewan Pendiri Lembaga Independen Dompet Dhuafa Republika. Namun, awal kelahiran Dompet Dhu'afa telah dimulai sejak kelahiran Harian Umum REPUBLIKA awal 1993, dimana wartawannya aktif mengumpulkan zakat 2,5\% dari penghasilannya. Dana tersebut disalurkan langsung kepada dhuafa yang kerap dijumpai dalam tugas. Dengan manajemen dana yang dilakukan pada waktu itu sia-sia, tentu saja penghimpunan maupun pendayagunaan dana tidak dapat maksimal.

Sesuai dengan ketentuan hukum yang berlaku, Dompet Dhuafa Republika tercatat di Departemen Sosial RI sebagai organisasi yang berbentuk Yayasan. Pembentukan yayasan dilakukan di hadapan Notaris H. Abu Yusuf, SH tanggal 14 September 1994 , diumumkan dalam Berita Negara RI No.

163/A.YAY.HKM/1996/PNJAKSEL. Berdasarkan Undang-Undang RI Nomor 38 Tahun 1999 tentang Pengelolaan Zakat, Dompet Dhuafa Republika merupakan institusi pengelola zakat yang dibentuk oleh masyarakat. Tanggal 8 Oktober 2001, Menteri Agama Republik Indonesia mengeluarkan Surat Keputusan Nomor 439 Tahun 2001 tentang
Pengukuhan Dompet Dhuafa Republika sebagai Lembaga Amil Zakat tingkat nasional. Dompet Dhuafa Republika berlokasi di Perkantoran Ciputat Indah Permai C28-29 Ciputat. Jl. Ir.H.Juanda No.50 Jakarta Selatan Telp.(021) 7416050, Fax: (021) 7416070.

Dompet Dhuafa Republika terus berkembang menjadi lembaga yang mendapat kepercayaan masyarakat www.dompetdhuafa.or.id. 02/09/2009). Salah seorang dewan pendiri Yayasan Dompet Dhuafa, Eri Sudewo, mengatakan bahwa Dompet Dhuafa Republika memantapkan posisinya sebagai lembaga yang modern dalam penggalangan dan pendayagunaan ZIS. Sampai tahun 1999 telah berhasil mengumpulkan dana lebih dari 11 miliar (Saidi, 2003: 47). Parni Hadi, salah seorang pendiri Dompet Dhuafa percaya bahwa kunci kesuksesan terletak pada kepercayaan dan profesionalisme (Saidi, 2003, 47). Oleh karena itu, Dompet Dhuafa Republika terus melakukan perubahan dalam sistem manajemennya agar lebih baik sesuai dengan kebutuhan.

Dompet Dhuafa mengembangkan pola marketing murni dalam pencarían donatur lewat direktorat penghimpunan. Direktorat ini membawahi divisi corporate marketing yang menggalang dana dari perusahaan dan divisi retail 
marketing yang menangani donor individual. Kegiatan penggalangan dana (fundrising management) pada tahun 2009 merupakan salah satu bagian dari tugas yang dinamakan Resources Mobilization (REMO). Resources Mobilizationmemiliki tugas penghimpunan dana, melakukan sinergi dan melakukan kerjasama (networking) (wawancara dengan Rovi Oktaviano hari Jumat tanggal 14 Agustus 2009).

Proses penghimpunan dana yang dilakukan Resources Mobilization melakukan tiga hal, yaitu:

a. Customer Relationship Management (CRM). Kegiatan CRM ada dua yaitu contact center dan customer process. Contact center yaitu salah satu bagian yang melakukan hubungan langsung dengan para muzakki. Sedangkan customer process melakukan kegiatan penjaringan muzakki sampai pencatatan menjadi donasi (www.dompetdhuafa.or.id dan wawancara penulis dengan Rovi Oktaviano hari Jumat tanggal 14 Agustus 2009).

b. Retail meliputi tiga bagian, yaitu:

1) Direct Channel yaitu penggalangan dana secara langsung. Dalam hal ini ada beberapa bagian, yaitu:pertama, kelompok donatur.Langkahlangkah sampai pada kelompok donatur ada beberapa macam metode atau strategi yaitu: (l) strategi direct mail(penggalangan dana lewat surat),mengumpulkan nama dan alamat yang dikumpulkan dari perusahaan atau asosiasi bisnis dan organisasi nirlaba, seperti IPHI, Ikatan Advokat, dll.Metode ini dilakukan pada masa awal Dompet Dhuafa berdiri sebagai upaya menjaring donatur. (2) media campaign,yakni penggalangan dana lewat kampanye di media. Media yang digunakan untuk kampanye adalah surat kabar harian Republika, tabloid Adil, dan tabloid Tekad. Penggunaan media tersebut karena sasaran utamanya adalah pembaca yang kebanyakan muslim. Tiga media tersebut dapat menjangkau tiga ratus ribu pembaca kalangan menengah dan berpenghasilan tinggi. Nama penyumbang dimuat dalam surat kabar tersebut serta ke mana dana zakat disalurkan.(3) membership, merekrut donatur menjadi anggota lembaga atau participan program. (4) special event, strategi ini dilakukan pada event-event tertentu seperti Hari Besar Islam. (5)zakat on-line dan Kartu anggota yang dinamakan Kartu Ukhuwah (KU) yang artinya kartu silaturahmi. Agar kartu ukhuwah ini bernilai, maka Dompet Dhuafa mengadakan perjanjian dengan Bank Komersial, Bank Mu'amalat Indonesia (BMI). Kartu Ukhuwah dapat berfungsi sebagai kartu ATM di BMI. Kedua, counter. Dompet Dhuafa membuka counter sebagai 
tempat layanan muzakki.

Counter reguler ada 5, sedangkan non reguler ada 7 .

Ketiga, membuka gerai. Gerai ini merupakan salah satu layanan tanpa ada orang yang menunggu atau memberikan layanan. Keempat, melakukan sosialisasi ke bank dan kelima, melakukan pengajian di perusahaan-perusahaan.

2) Partnership Channel, yaitu melakukan kerjasama dengan beberapa masjid yang berada di perumahan-perumahan atau perkantoran. Strategi ini menurut Rovi juga sebagai bagian dari dakwah yaitu mengajak kaum kaya untuk menunaikan zakat. (Wawancara penulis dengan Rovi Oktaviano selaku ketua divisi Resources MobilizationDompet Dhuafa, tanggal 14 Agustus 2009).

3) Marketing

Comunication

(Promosi). Promosi yang dilakukan melalui dua cara: yaitu: above the line yaitu promosi lewat media elektronik seperti radio atau televisi dan below the line yaitu promosi lewat media cetak seperti brosur, spanduk, dan lain-lain.

c. Corporate, yaitu menggalang dana zakat perusahaan.

Dalam melakukan kerjasama dengan perusahaan, Dompet Dhuafa menawarkan beberapa bentuk, yaitu:

1) Menawarkan program sosial seperti beasiswa atau bantuan sosial. Dana kegiatan dibiayai dari dana ZIS yang terkumpul dariperusahaan tersebut.

2) Program pendukung dimana perusahaan menyerahkan sejumlah dana untuk mendukung sebuah program Dompet Dhuafa. Sebagai contoh API (Asosiasi Pertambangan Indonesia), pertamina masing-masing menyerahkan uang sebanyak seratus juta rupiah dan sepuluh juta rupiah untuk mendukung program beasiswa yang dikembangkan Dompet Dhuafa.

3) Cause related marketing. Perusahaan menyisihkan keuntungan yang diperolehnya dari produk yang dijual atau dari transaksi penjualan. Misalnya, PT Dunkindo Lestari yang memproduksi makanan Dunkind Donuts menyisihkan Rp. 100,- (seratus rupiah) dari setiap transaksi yang terjadi di seluruh tokonya. (wawancara penulis dengan Divisi Fundrising, Rovi Oktavianotanggal 14 Agustus 2009).

Rovi mengungkapkan bahwa hasil yang diperoleh Dompet Dhuafa dalam menjaring dana zakat pada tahun 2008-2009 kebanyakan diperoleh lewat retail yaitu sekitar $78 \%$ dan kebanyakan para donatur bersifat individual. Sedangkan sumber zakat dari corporate (perusahaan) hanya 22\% (Wawancara dengan Rovi Oktavianotanggal 14 Agustus 2009). Dalam penggalangan dana Dompet 
Dhuafa meluncurkan program Zakat On-Line dan Internet Banking. Dengan metode tersebut, para muzakki dapat menyalurkan zakatnya dengan membayarnya lewat internet banking atau lewat debet rekening.

Gambaran di atas menunjukkan bahwa Dompet Dhuafa Republika telah melakukan suatu sistem fundrising dengan metode modern dan profesional serta menggunakan teknologi informasi dan komunikasi yang berlaku saat ini. Perkembangan teknologi informasi yang modern memudahkan akses bagi para muzakki dari kalangan menengah dan kalangan atas juga memudahkan kinerja bagi para amil (pegawai) Dompet Dhuafa sendiri.

Upaya penggalangan dana zakat (fundrising management) di Dompet Dhuafa dari hari ke hari terus meningkat dari segi kualitas dan kuantitas. Dilihat dari perkembangan yang ada, Dompet Dhuafa Republika terus melakukan perubahan dan perbaikan dalam melakukan fundrising. Semua itu membuahkan hasil dengan meningkatnya kepercayaan publik kepada Dompet Dhuafa Republika sehingga terwujud dalam berbagai bentuk karya nyata, baik dalam pendidikan, sosial, kesehatan serta pengembangan ekonomi masyarakat yang ditujukan bagi kesejahteraan kaum dhuafa.
3. Badan Amil Zakat Nasional Badan Amil Zakat Nasional (BAZNAS) dibentuk berdasarkan Keputusan Presiden No. 8 tahun 2001, tanggal 17 Januari 2001.Landasan Syar'i Berdirinya BAZNAS yaitu QS. al-Taubah: 103 "Ambillah zakat dari sebagian harta mereka, dengan zakat kamu membersihkan dan mensucikan mereka. Sesungguhnya doa kamu menjadi ketenteraman jiwa mereka. Dan Allah Mendengar lagi Maha Mengetahui." Jumhur ulama menyatakan bahwa yang berhak melakukan pengambilan sebagaimana kata "Ambillah" yang tercantum pada ayat tersebut adalah pemerintah. "Dari Ibnu Umar, semoga Allah meridlai keduanya. Ia berkata: Serahkanlah sedekah kamu sekalian pada orang yang dijadikan Allah sebagai penguasa urusan kamu sekalian". (HR Baihaqi). QS alTaubah, 60: "Sesungguhnya zakatzakat itu, hanyalah untuk orangorang fakir, orang-orang miskin, amil, para muallaf yang dibujuk hatinya, untuk (memerdekakan) budak, orang-orang yang berutang untuk jalan Allah dan orang-orang yang sedang dalam perjalanan". Badan Amil Zakat Nasional (BAZNAS) merupakan badan resmi dan satu-satunya yang dibentuk oleh pemerintah berdasarkan Keputusan Presiden RI No. 8 Tahun 2001 yang memiliki tugas dan fungsi menghimpun dan menyalurkan zakat, infaq, dan sedekah (ZIS) pada tingkat nasional (Sumber:www.baznas.go.id.28/01/20 $10)$. 


$$
\text { Lahirnya Undang-Undang }
$$
Nomor 23 Tahun 2011 tentang Pengelolaan Zakat semakin mengukuhkan peran BAZNAS sebagai lembaga yang berwenang melakukan pengelolaan zakat secara nasional.

Tugas pokok BAZNASadalah merealisasikan misi BAZNAS yaitu: 1) Meningkatkan kesadaran umat untuk berzakat; 2) Mengarahkan masyarakat mencapai kesejahteraan baik fisik maupun non fisik melalui pendayagunaan zakat; 3) Meningkatkan status mustahik menjadi muzakki melalui pemulihan, peningkatan kualitas SDM, dan pengembangan ekonomi masyarakat; 4) Mengembangkan budaya "memberi lebih baik dari menerima" di kalangan mustahik; 5) Mengembangkan manajemen yang amanah, profesional dan transparan dalam mengelola zakat; 6)Menjangkau muzakki dan mustahik seluas-luasnya; 7) Memperkuat jaringan antar organisasi pengelola zakat. Kegiatan pokok BAZNAS adalah menghimpun ZIS dari muzakki dan menyalurkan ZIS kepada mustahik yang berhak menerima sesuai ketentuan agama.BAZNAS merupakan lembaga pengelola zakat tingkat nasional. Jaringan pengelola BAZNAS ada di seluruh nusantara yang terdiri dari 33 Badan Amil Zakat Daerah Tingkat Propinsi (Sumber:

www.baznas.go.id.28/01/2010), 240 Badan Amil Zakat Tingkat Kabupaten/Kota dengan BAZ Kecamatan, 30 Lembaga Amil Zakat Tingkat Pusat, 84 mitra pelayanan Zakat Nasional dan KBRI/KJRI (Sumber: www.baznas.go.id28/01/2010), 19 mitra Unit Salur Zakat Daerah (Sumber: www.baznas.go.id.28/01/2010). Jaringan Pengelola Zakat adalah bidang yang memiliki tugas untuk melakukan kemitraan dengan Organisasi Pengelola Zakat. Pengembangan jaringan memiliki konsen untuk mendampingi Organisasi Pengelola Zakat (OPZ) dalam hal pengembangan organisasi dan kemitraan dengan lembaga sejenis. Bidang ini juga bertanggungjawab untuk melakukan koordinasi pengumpulan database OPZ secara nasional.Dengan banyaknya Unit Pelayanan Zakat (UPZ) yang tersebar di beberapa departemen dan Kantor Kedutaan yang berada di beberapa negara menjadikan BAZNAS sebagai Badan Amil Zakat yang memiliki jangkauan sangat luas.

Strategi pengumpulan dana zakat dilakukan BAZNAS melalui berbagai cara, yaitu: pembentukan Unit Pengumpul Zakat (UPZ), Kerjasama program PKBL dan CSR, donasi retail dana kemanusiaan, pembayaran lewat conter layanan ZIS, melalui UPZ mitra BAZNAS, melalui bank: ATM (transfer, phone andinternet banking), layanan jemput zakat, layanan donasi lewat SMS, pendaftaran lewat zakat online, dan lain-lain (Sumber: www.baznas.go.id.28/01/2010).

Strategi fundrising yang dilakukan BAZNAS hampir sama dengan strategi yang dilakukan oleh Dompet Dhuafa Republika. BAZNAS memiliki jaringan lebih luas dan menjangkau semua wlayah Nusantara. Sebagai Badan Amil 
Zakat Nasional,, BAZNAS dituntut untuk menjadi lembaga yang profesional.

Jenis dana yang dihimpun oleh BAZNAS berupa zakat, infaq, shadaqah, dana CSR \& $\&$ BL, comdev perusahaan, dana hibah, dan lainlain. Zakat yang diterima BAZNAS berupa zakat profesi, zakat penghasilan, perdagangan dan perusahaan, pertanian dan peternakan. Adapun analog (qiyas) yang diguankan dalam nishabnya adalah sebagai berikut:Zakat Profesi analog dengan zakat pertanian (qiyas syabah) yaitu setara $524 \mathrm{~kg}$ beras, kadar: $\quad 2,5 \% \quad$ dari penghasilan,pembayaran setiap menerima penghasilan (tidak ada haul), penghasilan bruto (Sumber: Company Profile BAZNAS, 2010).

Dengan banyaknya unit pengumpul zakat yang tersebar di beberapa tempat menjadikan BAZNAS memiliki peluang besar dalam menghimpun dana zakat dari masyarakat. Keberadaan unit pengumpul zakat yang biasa disebut UPZ berperan dalam mengumpulkan dana ZIS yang terkumpul dari para mustahik dan selanjutnya disalurkan ke BAZNAS.

Strategi fundrising BAZNAS terletak pada kekuatan pola kerjasama atau kemitraan yang dibangun baik dengan pemerintah ataupun swasta, seperti perusahaanperusahaan, perbankan syariah dan lain-lain. Hal demikian menjadikan lembaga BAZNAS yang mendapat kepercayaan masyarakat sehingga memberikan dampak besar bagi kesejahteraan ummat.
4. Badan Amil Zakat Infak dan Shadaqah DKI Jakarta

Badan Amil Zakat Daerah (BAZIS) DKI Jakarta merupakan salah satu BAZDA pertama di Indonesia. BAZIS DKI Jakarta didirikan oleh Gubernur Ali Sadikin dengan surat keputusan No. Cb. 14/8/18/68 tanggal 5 Desember tahun 1968 tentang Pembentukan Badan Amil Zakat, berdasarkan syariat Islam dalam wilayah DKI Jakarta. Selanjutnya pada tahun 1973 Gubernur DKI Jakarta mengeluarkan surat keputusan No. D.III/B/14/6/73 tanggal 22 Desember 1973 berisi penyempurnaan BAZ menjadi Badan Amil Zakat dan Infaq/Shadaqah yang berisi penyempurnaan BAZ menjadi Badan Amil Zakat dan Infaq/Shadaqah yang disingkat menjadi BAZIS

(Sumber:www.bazisdki.go.id).

Sebagai BAZDA yang lebih awal berdiri menjadikan BAZIS DKI memiliki pengalaman cukup lama dalam manajemen zakat.

Sesuai dengan Peraturan Gubernur DKI Jakarta Nomor 51 Tahun 2006 Bab III Pasal 7, pengumpulan ZIS dilakukan dengan tiga cara, yaitu: a) melalui petugas operasional; b) melalui bank; dan c) melalui petugas pemungut yang ditunjuk. Ada beberapa hal terkait dengan manajemen penghimpunan ZIS di BAZIS DKI Jakarta, yaitu:Sasaran.Sasaran penghimpunan ZIS adalah seluruh warga muslim ibu kota yang dikelompokkan menjadi 
enam kelompok, yaitu:1) Masyarakat umum yang dikoordinasikan oleh Kepala Kelurahan yang dibantu oleh Ketua RT/RW serta tokoh agama atau pemuka masyarakat; 2) Karyawan/pegawai yang dikoordinasikan oleh kelurahan, kecamatan, kotamadya dan BAZIS unit Satuan Kerja; 3) Para pengusaha nasional, hartawan, dan dermawan yang dikoordinasikan langsung oleh BAZIS Provinsi DKI Jakarta atas nama Gubernur; 4) Infaq dan shadaqah lewat SMS; 5) Nasabah bank; 6) Jamaah calon haji dan umroh.

Berdasarkan data tersebut, BAZIS DKI Jakarta memiliki dua kelompok muzakki ada yang tetap seperti pegawai di lingkungan pemerintah daerah DKI Jakarta maupun yang tidak tetap seperti masyarakat umum termasuk pengusaha. Kondisi tersebut mempermudah penghimpunan dana. Strategi BAZIS DKI Jakarta dalam menghimpun dana menggunakan pendekatan struktural yaitu Pemerintah DKI Jakarta yang memiliki wewenang penuh.

Salah satu petunjuk pelaksanaan pengumpulan dan pendayagunaan ZIS di DKI Jakarta yaitu Peraturan Gubernur Daerah Khusus Ibukota Jakarta Nomor 51 Tahun 2006 tentang Petunjuk Pelaksanaan Pengumpulan dan Pedayagunaan Zakat, Infaq dan Shadaqah oleh Badan Amil Zakat
Provinsi DKI Jakarta. Dalam Peraturan Gubernur tersebut diatur tentang mekanisme pengumpulan ZIS serta tugas kerja bagian unit kerja pengumpul ZIS. BAZIS DKI Jakarta secara struktur meliputi BAZIS Provinsi, BAZIS Kotamadya, dan BAZIS Kelurahan/Kecamatan. Setiap tingkat masing-masing BAZIS di DKI Jakarta memiliki sasran muzakki, munfiq, dan mutashaddiq tersendiri.

Muzakki untuk tiap jenjang wilayah diatur dalam Pasal 2 Bab II Peraturan Gubernur Daerah Khusus Ibukota Jakarta Nomor 51 Tahun 2006 tentang Petunjuk Pelaksanaan Pengumpulan dan Pedayagunaan ZIS BAZIS Provinsi DKI Jakarta. Gambaran struktur BAZIS DKI Jakarta sesuai dengan petunjuk Undang-Undang No.38 Tahun 1999 tentang Pengelolaan Zakat yang tercantum dalam BAB III pasal 6 . Struktur organisasi BAZIS berdasarkan struktur/susunan tata pemerintahan yang berlaku saat ini mulai dari Tingkat Provinsi, Kabupaten/Kotamadya, sampai Kecamatan dan Kelurahan. Pembagian tugas serta sasaran para muzakki, munfiq, dan mutashaddiq akan mempermudah para pegawai/amil dalam melakukan pendataan sehingga memperlancar pengumpulan zakat.

Strategi pengumpulan ZIS yang dilakukan BAZIS DKI Jakarta meliputi:l) Membangun kerjasama 
teknis dengan lembaga/instansi lain dalam hal penyuluhan dan penghimpunan ZIS; 2) Melakukan koordinasi, integrasi, dan sinkronisasi yang bersifat teknis (bukan kebijakan) dengan semua pihak, agar penghimpunan ZIS optimal; 3) Bekerjasama dengan lembaga profesi sejenis sebagai mitra atau sinergi dalam penyuluhan zakat, infaq, dan shadaqah.

BAZIS DKI Jakarta telah menggunakan prinsip-prinsip manajemen dalam pengumpulan ZIS. Upaya sosialisasi program dan kegiatan BAZIS DKI dilakukan beberapa cara, yaitu: media cetak, media elektronik dan media lisan. BAZIS DKI Jakarta menggunakan media telekomunikasi dalam mensosialisasikan programnya sesuai dengan kondisi masyarakat yang ada. Media telekomunikasi juga merupakan sarana yang memberikan kemudahan dan kecepatan sehingga dapat menghemat waktu. Semua itu bertujuan untuk meningkatkan performance-nya agar kehadirannya dapat dirasakan oleh masyarakat. Penggunaan media yang lebih mudah diakses akan memudahkan komunikasi antara BAZIS dengan muzakki, munfiq maupun mutashaddiq. BAZIS DKI Jakarta merupakan Badan Amil Zakat Daerah pertama yang berdiri di Indonesia. Sehingga keberadaannya dapat menjadi percontohan bagi Badan Amil Zakat Daerah lainnya di
Indonesia. Secara kelembagaan, Badan Amil Zakat milik pemerintah sehingga memiliki peluang lebih besar dalam hal pemungutan zakat apabila pihak pemerintah yang memiliki kekuasaan tertinggi dapat memberi dan mengajak jajaran di sekitarnya untuk berzakat.

Hal ini dapat dilihat pada kebijakan pemerintah DKI Jakarta dimana dalam event-event tertentu seperti ramadhan, gubernur DKI merupakan pelopor. Selain itu, pemerintah daerah membuat peraturan yang mengatur regulasi zakat untuk tingkat daerah.

\section{Kesimpulan}

Berdasarkan uraian di atas dapat disimpulkan bahwa strategi penggalangan dana (fundrising) yang dilakukan lembaga fillantropi di Indonesiaadalah sebagai berikut:pertama, media yang digunakan: Cetak, elektronik, internet, dan media komunikasi. Dalam hal ini ada beberapa cara, yaitu: (1) Media Compaign yaitu penggunaan media yang mempublikasikan kelompok masyarakat yang membutuhkan bantuan atau yang mendapatkan kesulitan. Dalam hal ini ada bentuk berita dan undangan suatu kegiatan. Selain itu, ada juga forum dialog atau diskusi dengan wartawan dan kunjungan ke media massa. (2) Direct mail, yaitu penyebaran brosur untuk menjaring donatur tetap (muzakki). (3) Telefundrinsing, yaitu dengan melakukan 
kontak dengan muzakki. Telepon dilakukan sebagai tindak lanjut (follow up) dari brosur yang sudah diisi oleh calon muzakki. Apabila sudah menjadi muzakki tetap, telefundrising ini digunakan untuk mengingatkan muzakki tentang kewajibannya menunaikan zakat. (4) Direct fundrising yaitu dengan cara berinteraksi langsung dengan para muzakki yang dikenal dengan istilah jemput zakat. Di DPU DT petugas penjemput zakat disebut Timsil (Tim silaturrahmi).

Kedua, model penghimpunan dana lembaga-lembaga filantrofi adalah melalui: (1) Kerjasama program biasa dilakukan antara lembaga zakat dengan perusahaan dalam bentuk kegiatan yang dibiayai oleh perusahaan atau pemilik dana. (2)Special event, yaitu sebuah kegiatan untuk mengumpulkan dana. Misalnya, peringatan hari besar, konser amal, dan lain-lain. (3) Religius Fund. Metode ini digunakan lewat pengajian atau ceramah. (4) Pembentukan Unit Pengumpul Zakat (UPZ), Kerjasama Program PKBL dan CSR, Donasi ritail dana kemanusiaan, pembayaran lewat konter layanan ZIS, melalui UPZ Mitra BAZNAS. (5) Melalui bank: ATM (transfer, phone \& internet banking), layanan donasi lewat SMS. (6) Zakat on-line.

Ketiga, pada awal pendirian lembaga filantrofi Islam cara penghimpunan dana ditempuh beberapa cara: (1)Dimulai dari suatu kegiatan sosial melalui penggalangan dana. (2) Kebijakan pemerintah. (3) Penyebaran brosur. Selanjutnya, strategi pengembangan dan penggalangan dana dilakukan dengan memanfaatkan peluang dan potensi yang dimiliki oleh lembaga.

\section{DAFTAR PUSTAKA}

Juwaini,Ahmad.2005.Panduan Direct Mail Untuk Fundrising. Depok: Piramedia.

BAZIS Provinsi DKI Jakarta \& Institut Manajemen Zakat.2006.Manajemen ZIS BAZIS Provinsi DKI Jakarta. Jakarta: BAZIS Provinsi DKI Jakarta.

BAZIS DKI Jakarta.2006.Peraturan Gubernur Provinsi DKI Jakarta. Jakarta: BAZIS Provinsi DKI Jakarta.

Tim Penyusun.2006.Manajemen ZIS BAZIS Provinsi DKI Jakarta. Jakarta:BAZIS Prov. DKI Jakarta.

Saidi,Zaim.Dkk.2003.Strategi dan Pola Penggalangan Dana Sosial di Indonesia Pengalaman Delapan Belas Lembaga Sosial. Jakarta: Pustaka Pelajar Offset.

Tanpa Pengaran. 2007. Undang-Undang RI. No. 38 Tahun 1999 Tentang Pengelolaan Zakat. Bandung: Citra Umbara.

http//:www.dompetdhuafa.or.id

http//www.bazisdki.go.id, email:webmaster@bazis dki.go.id

Hasil Wawancara penulis dengan manajer Fundrsing DD Republika

wawancara penulis dengan Manajer fundrising DPU DT

Sumber: www.baznas.go.id.

Sumber: www.dpu-online.com 